\title{
Towards the Strategies for English Vocabulary Development
}

\author{
Xueyun Zang \\ School of Foreign Languages, \\ Qilu Normal University \\ Jinan, China \\ e-mail: andyzangxueyun@163.com
}

\author{
Ya Lu \\ School of Foreign Languages, \\ Qilu Normal University \\ Jinan, China \\ e-mail: 1379236986@qq.com
}

\begin{abstract}
This paper explains vocabulary development from two aspects of strategy and understanding. In order to enlarge vocabulary and strengthen learning effects, students must have a clear understanding of necessity of learning vocabulary; which words attract our attention and then we can form effective strategies for vocabulary learning.
\end{abstract}

Keywords—learning strategies; English words; vocabulary development

\section{INTRODUCTION}

For many Chinese English learners, vocabulary becomes one of the most difficult parts in the whole process of English learning: we understand the meaning well but when speaking, we do not know how to express ourselves because we lack the words. The problem, which shames learners most, is forgetting what they are trying to memorize. It is true that lack of words will surely influence other language knowledge and skills. So as English learners, have you ever asked yourself why we achieve so little after spending so much time and effort on the study of words? In this paper, we are trying to solve this problem.

\section{IMPORTANCE AND NECESSITY OF ENGLISH VOCABULARY LEARNING}

The importance of learning words in English is considered as following from the views of some great language experts:

"Learning, acquisition and mastery of words are essential to the successful study of English after the primary stage"

"A considerable vocabulary serves as a solid basis for further English learning. Without this basis, it is impossible to get understandable, interesting and vivid language information, and let alone the fluent use of language."

"If communication is considered to be the first aim in foreign language learning and if, lacking free control of this new language, words, which can make people fulfill the most basic communication, becomes vital."

"Students always take dictionaries rather than grammar books with them."

More and more linguists and foreign language teachers become aware that, for students, especially those with middle or advanced levels of foreign language, the biggest difficulty and the first need lie in enlarging their vocabulary. Despite this, there still exists a large gap in people's understanding of the importance of learning words. Whether designing outlines, compiling textbooks, or arranging lessons, foreign vocabulary learning has not been attached to sufficient importance. People's attention is focused on syntax and grammar. It is even said that without the teacher's definite explanation and instruction, words can be mastered indirectly during the grammar drills, communicative activities and reading. In this case, English vocabulary learning is regarded as an automatic and subconscious act, which obviously makes vocabulary learning blind and out of order.

This leads to the difficulties in word study. Some Chinese college students hold such opinions about vocabulary learning " words learned from lessons cannot be applied to real life, so it is hard to remember them."; "Memorizing words is boring, mechanical and uninteresting."; "In class, we have no idea how to use these words, while after class, we have no idea where to use them." These opinions truly inflect the situation of learning words in China. While facing the situation, we are left to solve the problems.

The first requirement of The English Teaching Syllabus is vocabulary, which demands a comprehensive mastery of 4200 words as well as the usual phrases formed by these words, while the higher required vocabulary even reaches to 5500 . Actually, as far as reading is concerned, extensive research shows that 6000-8000 words are enough for students. The figure from Dutch researcher is 10000. Most British and American students have an English passive-reading vocabulary of 60000-150000 on average.

From the number required by reading, we know that there is no doubt that acquiring and enlarging vocabulary has become a tough task for Chinese English-language-learning students. To achieve this goal, hard work, careful research, and mutual cooperation are needed for both teachers and students.

\section{PROBLEMS EXISTING IN LEARNING WORDS}

In the process of learning words, learners are usually lacking in theory to guide their study. It is discovered that they learn words in the following mistaken way: 
- Words are learned and memorized in an isolated way. Without proper language environment, there is no way for students to master words completely.

- Pay mere attention to words' spellings, neglecting their pronunciation.

- Students wish they could learn a considerable number of words overnight. Blind pursuit of "quantity" and "speed", without reasonable analysis or necessary understanding, can achieve no solid basis of vocabulary.

- There is a shortage of complete and deep understanding in systematic vocabulary knowledge such as words' function, definition, meaning, style, emotion, association, matching, etc.

- Students focus on learning and memorizing words, while they ignore their application.

- There are some interference from native language, such as "tagging" the English words in native language sounds, being over dependent on translation, totally leaning on Chinese explanation from English Chinese dictionaries.

- There is no accumulation or repetition. Learn words quickly; forget them in haste.

It has been proved that words must be learned comprehensively and systematically. If words are learned in an isolated way, English learners can achieve little.

Of course, there are various factors affecting English vocabulary learning in China. Some lie in students themselves. Some result from the general teaching arrangement and specific teaching planning. On the whole, such factors also affect the acquisition of foreign words. Generally speaking, the factors are the following: characteristics of foreign language, characteristics of native language, and characteristics of students (such as personalities, motives, learning attitudes, previous knowledge, etc.), studying environment, and rate of forgetfulness, different studying ways, and students' skill in how to learn words and how to memorize them.

\section{MASTERY OF ENGLISH VOCABULARY}

As we all know, English has a large vocabulary. However, there are not many words used by English native speakers in their daily life. It is roughly estimated that there are 5,00o or so. But these words are used with high frequency. These words are very important and need students' effort and time. Usually students should concentrate on learning these words within a certain period and master the words. For these high-frequency words, it is not enough to know their surface meaning. So how can we say we really master a word? Mastering a word means:

- Be clear about its pronunciation.

- Know its literal meaning

- Master its derived forms. For example, from "work" can derive "worker", "working", "workman", "workbook" and so on.
- Know the expanding meaning. For example, "foot" means not only part of the human body, but also the bottom of a place. For example, "the foot of the mountain"

- Know its meaning as well as meanings of related words. For example, the word "mother" is always related to the following meanings like "love, care, tenderness, forgiving".

- Be clear about its grammatical characteristics.

- Know choices of words according to different situations. For example, the words "tremble" and "quiver" have similar meanings, but the frequent matching phrases are "tremble with fear" and "quiver with excitement".

- Understand types of writing, such as oral types or written types. For example, word "domicile" is the official language, residence is the written language, and home is oral.

- Understand words' cultural origin. For example, the word "pen" used to mean "feather", because people at that time used feather pen to write.

- Be clear about the grammatical sense of words, eg: derogatory; commendatory etc.. For example, "dear old soul" belongs to the commendatory, "old man"neuter, while "old witch" is derogatory.

Besides the above ten aspects, English learners should achieve the ability of using a word fluently and automatically. This is the way to measure the degree of mastery and check whether fulfilling the aim of learning words.

\section{THE UnDERSTANDING OF VOCABULARY DEVELOPMENT}

\section{A. The Unit of Words}

Though words are compared to rocks and bricks in "skyscraper" of language, words are not the smallest meaningful formation units. Linguists define the smallest, indivisible parts of meaning as morpheme. Some words only have one morpheme, such as dog and meat. Some have two. Kindness is made up of two morphemes: "kind" and "ness". Some have three, such as "unfriendly" having "un", "friend" and "ly". Understanding these would be helpful for students to know different formations of words and remember them accordingly.

\section{B. Words Study to be a "must"}

Students' answer to the question is always "to learn English well". It is true, but it is too general to be practical. As a matter of fact, different students have different learning targets. Even the same learner has different learning targets in different learning stages. It is also true in vocabulary learning. Every student has different understandings of vocabulary learning. Ask yourself: at your present stage, why do you have to learn English words?" The answer to this question can directly influence choices of learning vocabulary and application of vocabulary learning strategies. Many people attend tests like TOEFL, GRE or different kinds of entrance examinations. 
Examples such as TOEFL and GRE can illustrate that different purpose of learning can influence the ways of learning directly.

Every language learner must have a clear idea about why one should learn words and apply targeted ways according to specific purposes.

\section{Words to be Learned}

There are over one million English words. There far fewer in the Chinese vocabulary. But not all English words need be mastered. The usual English words are not more than 10,000. The most commonly used words in daily life are even less, about a few thousand. Considering wide sources of learning materials, varied subjects and styles, some unusual words are unavoidable. Some students have a habit of consulting the dictionary for every unknown word, which makes memorizing more difficult. It is not that difficult words like "trigonometry", "guillotine", "obituary" and "hyena" are not important themselves, just that they are not used frequently.

As to choosing which words to learn, learners need to set up a general direction first. Students should bear in mind which words should be learned during a specific stage. For example, in middle school, great importance should be attached to learning and mastery of the most basic and frequently used words in daily life. Generally speaking, most words in textbooks belong to this kind. Therefore middle school students should pay much attention to learning words in textbooks and try to learn a vocabulary 5,000 or 10,000 . If energy permits, middle school students can expand their vocabulary by extracurricular reading. In addition to the mastery of basic vocabulary, college students should learn more words related to their own majors in order to read professional and original English materials. People at work should also expand their vocabulary to meet the needs of their jobs.

After setting up the direction of vocabulary learning, one should learn each word in different ways. Here is the scientific approach: to learn to judge the importance of new words and the necessity to memorize them. Maybe one will ask: I even don't know the word, so how could I decide its importance and the necessity to memorize it? Points of reference are given as following:

- To judge whether the new word influence the comprehension of the whole text. If it doesn't affect the understanding of the sentence, it could be consider as unimportant. At least it is not important in the environment of that sentence.

- To find out the frequency of the appearance of the new word. Generally speaking, in a text, high-frequency appearance of some words proves their importance (except terms).

- To know whether you are familiar with the new word or not. Vocabulary can be divided into three parts: known words, familiar words and unknown words. The most effective way to learn is to study the familiar words and to memorize them.

There is no absolute criterion for judging the importance of one word. Some are significant, some are important and others count for few things. We should pay much attention to the significant words, guess the important one and leave the unimportant ones aside. Maybe we will never meet such words again, so why bother to memorize them?

\section{To what extent the words to be Learned}

Is it good to master the meaning of words firmly? Actually, every coin has two sides.

Of course it is necessary to master all the common meanings of the words. But in fact many people can only master one or two meanings of one word. In this case, when learners meet with such kinds of words, the mastered meaning will quickly rush into their brain. First impression is strongest. So it will probably hinder the other possible meanings, influencing the understanding of the whole text. For example:

A: Can we meet sometime next week?

B: Well, let me have a look at my diary.

Next morning I found a foot of snow on the ground.

Every vote counts.

From these examples we can find out that it will take much time to memorize some meanings of one word firmly. Firmly memorizing parts of words means that you will not have enough time to memorize other words. Similarly, firmly memorizing one meaning of some words leads to the forgetting of the meaning of others.

So, in English, besides those mostly-commonly-used words, there is no need to memorize the generally-common-used words very firmly. If we can understand the meaning in the context, we just leave them alone and take more time to do extra reading. With more reading, we can contact more meanings and usages of words.

\section{E. Is there any shortcut for memorizing words?}

Few foreign language learners are not worried about memorizing words, but few people can understand that memorizing is the hardworking process of fighting against forgetting from the view of psychology. Linguists pay much attention to the structural problems in language such as stem, affix or structural rules of language. It will be helpful to memorize words to know about imaginative function between synonyms and antonyms.

Word family memorizing is contained in the method of combination of meaning and structure, which is an effective way in memory. There are many kinds of methods such as the participation of many senses, using surrounding the environment, picking up short time everyday or some special personal ways, for example, to recite the dictionary. They will be efficient and helpful for different people.

\section{F. How to memorize words effectively?}

Here are some questions students usually ask:

- Why do I always forget words?

- Why can't I enlarge my vocabulary? 
The reasons perhaps are:

- Students memorize words in an isolated and monotonous way such as only memorizing the spelling and meaning but without pronunciation and classification.

- Words must be used in context. Without text environment, the word is meaningless. If you don't know the match, change and words family, even if you hear and see it later, you will not understand it. And practical use will be impossible.

So how can we memorize words effectively?

Firstly, the key point is that we memorize words to make our listening, speaking, writing and reading easier. Then, in the process of receiving information, that is, during your listening and reading, you'd better memorize the typical sentence which contained the new word. Don't consider memorizing a sentence as a burden to your brain. To the contrary, those vivid interesting sentences will not only make you freshen up, but also can inspire your imagination and make you learn by analogy. For examples: rise can be defined as "become or be visible above the surroundings". This explanation is too long and vague. But we can use a sentence to memorize such as "A range of hills rose on our left." Then we can create a sentence as "A tall building rose on our right."

This is using imaginative thinking to memorize words, but sometimes this method seems to be too slow when we are going to take part in an exam or an oral interpretation. So we should memorize a large number of words by means of logical thinking.

The most effective way is using words formation. There are some kinds of words formation as follows:

- affixation: television northwestward returnees

- composition: bathtub classroom drugstore

- blending: motel smog boatel

- backformation: babysitter

- shortening: ad. flu fridge

- acronym: UFO UN WTO

If we can understand all the ways of word formation, it will be simple for us to memorize words and even better for knowing the origins of words.

Besides the specific methods mentioned above, we still have the method of word family: nation; national; nationality; nationalism; nationalist; international; the method of memorizing words by imagination and match: take; take a trip; take a lunch; take a nap and method of memorizing words by antonyms and synonyms

All in all, whichever way you choose to memorize words, the most important thing is that you can use words to make sentences, send messages and express your own feelings. If you can use the words to express your own viewpoints freely, then how can you not memorize them firmly?

\section{G. How can we avoid forgetting effectively?}

Memorizing is a significant and necessary method to learn any foreign language. Some scholars even consider the process of learning a foreign language as a memorizing process. Words, sentences and grammar all depend on memorizing. At the same time, firm and rich memory is fundamental to improving our foreign language. We know that memorizing keeps information in our mind while forgetting does the opposite.

While learning a foreign language, how can we avoid forgetting effectively? Confucius Kong said that "we know new things by reviewing". It tells us that reviewing is the "mother" of memorizing. The speed of forgetting often slows down gradually from beginning to end. Therefore we should do the reviewing as soon as possible. Sometimes excessive study can effectively reduce forgetting. What's more, reviewing after studying is the necessary method to enforce memorizing.

Secondly, we should allocate our reviewing time reasonably to achieve the most success by the least work. The allocation of time should be appropriate. We should review the interesting and relatively simple knowledge together such as the general meaning of a text or the phrases and expressions in the text. And then we come to review the difficult and dull ones little by little such as grammar or spelling.

When doing reviewing work, it is better to try to recall everything actively. Usually we cann't help opening books and looking for answers when we forget some word spelling or grammar. Actually, it is a passive method of reviewing. For instance, when we forget some grammar rule, we can guess the probable meaning from its grammatical name, and then come to the book.

We should also review in diverse ways. Reviewing is repeating using. Only one method will make you feel bored and tired and reduce the efficiency of reviewing.

After all, it is normal to forget what we have learned. The key point is to pick up the most effective way to memorize words and avoid forgetting.

\section{STRATEGIES IN DEVELOPING ENGLISH VOCABULARY}

\section{A. To learn words in context}

1) By means of antonyms and synonyms in context.

A study of more than 12,000 American teenagers found that young people who spend more time with parents are happier than... It was also found that kids who spend more time with their parents do better in their school subjects.

In this passage teenagers and kids have a similar meaning. We know the meaning of kids and then we deduce the meaning of teenager from the context.

2) By means of demonstrating relationship between words in context.

Mick's father always went out in the evenings. One day Mick said to his father, "My friends always watch TV with their parents. They ask a lot of questions. But in our home, mom seems to be the only parent." These comments caused the father to begin to think. 
According to the context of this short passage, "comments" encapsulates the meaning of all the words. Another example: Susan went to the shop and bought some bananas, mangoes, and rambutans. Of course, we know rambutans refer to a kind of fruit.

3) By means of word match in the context.

I am going to have a party to celebrate my 20th birthday. In this sentence it is not difficult to guess the meaning of celebrate because we can deduce the meaning from birthday.

Let's synchronize our watch so that we can start the game at the same time. With the help of watch and the same time, the meaning of synchronize appears to be very clear.

\section{B. To enforce learning efficiency by imagination.}

Here is a group of words: house, kitchen, bedroom, bathroom, sitting room, cupboard, clock, stove, TV, video, toothpaste, dressing table, towel, shower, slippers, sofa, mirror, wash, basin. We can use our imagination to add more words relating to such a group.

\section{To enforce the comprehension of words by classification}

Which kinds of clothes are for men's wear? Which kinds are for women? Which kinds are for both?

Overcoat, gloves, raincoat, trousers, suit, T-shirts, sweater, coat, skirt, jacket, west, dress, blouse, shorts, stockings, scarf, jeans, socks

\section{To enhance word retention by learning synonyms and} antonyms

For example, can you find the 6 pairs of antonyms and 6 pairs of synonyms among the following words?

Abroad, astonish, believe, common, danger, dear, defeat, doubt, expensive, failure, hanger, home, priceless, proposal, rescue, safety, save, shock, starvation, success, suggestion, unusual, valuable, victory

\section{CONCLUSION}

Vocabulary development is difficult for many English learners. With effective memory strategies, however, it is possible to attain word power very quickly. Useful strategies discussed in this part will guide our learning. Of course, learners must explore vocabulary development strategies that are most effective for themselves.

Learning words is a hard job. It needs time, effort and skills. Due to its importance in mastering English language, learners are left no choice but come to the study and research of words as a whole. With knowing what a word is and what a word means and with a good command of strategies, English learners will come to master the words which are necessary.

\section{REFERENCES}

[1] Brown, H. Douglas. Principles of Language Learning and Teaching [M]. New Jersey: Prentice Hall, Inc.1987.
[2] N. Wolfsan, Language and Communication [M]. London: Longman, 1983.

[3] Cheng Xiao Tang. Learning Strategies for English Study [M].Being Jing: Foreign Languages Teaching and Research Press , 2002.

[4] Bai Renli. Instruction and Practice for English Words Study[M].Shang Hai: Fudan Un iversity Press,2001. 